\title{
Flash evoked responses in a song control nucleus of the zebra finch (Taeniopygia guttata castanotis)
}

\author{
HANS-JOACHIM BISCHOF and JÜRGEN ENGELAGE \\ University of Bielefeld, Department of Ethology, P.O. Box 8640, D-4800 Bielefeld, (F.R.G.) \\ (Accepted September 17th. 1984 )
}

Key words: zebra finch — visually evoked potentials - hyperstriatum ventrale pars cauditle

\begin{abstract}
The song of the zebra finch is facilitated and altered by the presence of a female. Thus, visual information should affect the song system of the bird. Visually evoked potentials can be recorded from $n$. hyperstriatum ventrale pars caudale (HVc). The long latericy of this potential and its variability indicate several processing steps between primary sensory areas of the telencephalon and HVC. Within $\mathrm{HVc}$, under these experimental conditions no interaction between acoustic and visual input could be demonstrated. However, at the dorsal border and within the shelf below HVc, visual information seems to enhance acoustically evoked potentials.
\end{abstract}

The song of oscine birds is controlled by a well-defined system of concatenated brain nuclei, the socalled song system ${ }^{13}$. As feedback control is necessary for development and for performance of song in many of these birds 8 , connections from the auditory system to the song control system have been proposed and could be demonstrated by several authors ${ }^{5-7.10 .11 .14}$. According to their results, the nucleus hyperstriatum ventrale pars caudale $(\mathrm{HVc})$ receives input from field $L$, the telencephalic nucleus of the auditory pathway in the bird's brain.

The song of the male is, at least in the zebra finch, facilitated by the presence of a female. It could be demonstrated that quality and quantity of the male's song is altered by presentation of a living female as well as by a female dummy or even a picture of a female ${ }^{1-4}$. With increasing similarity of the stimulus to a living female the song of the male becomes more stereotyped and frequent and has more introductory elements and motifs. Based on these song features. two different song types can be detected under natural conditions: the so-called 'undirected' song which is uttered in situations not clearly associated with a definite function; and the 'directed' song, which is directed towards the female and combined with courtship display ${ }^{4} \cdot 12,15$. Solely acoustic contact with a female is not sufficient to elicit courtship behavior and directed song (Bischof, unpublished results).

From these behavioral studies it is likely that the song control system is in some way affected by visual information. However, there are no data available concerning connections between the visual system and song control nuclei. Thus we decided to examine directly whether the song system receives visual input. For this purpose, we tried to record visually evoked potentials (VEPs) from HVc, while one of the bird's eyes was stimulated with flashes.

$H V c$, a higher order nucleus of the song control system, was chosen, because it receives acoustic input (see above). We proposed that most likely acoustic and visual influences should interact for the control of song elicitation. Evoked potentials were recorded with glass electrodes (K-citrate $10-40 \mathrm{M} \Omega$ ) from the HVc of 20 adult male zebra finches. The birds were anesthetized with Urethane $(20 \% \mathrm{w} / \mathrm{v}$, $0.1 \mathrm{ml}$ ). Visual stimuli were provided by a stroboscope; the flash was directed to the contralateral eye by a fiber-optic system. Clicks were given as an acoustic stimulus by earphones connected to the hollow earbars by $2 \mathrm{~cm}$ length of very flexible vinyl tubing. Three different combinations of stimuli were used throughout the experiments: contralateral acoustic stimulation, contralateral visual stimulation and a combination of both. In addition controls were made by disconnecting the earphones from the earbars and displacement of the fiber optics or simply switching off the triggers.

The signals were usually averaged 64 times by a 

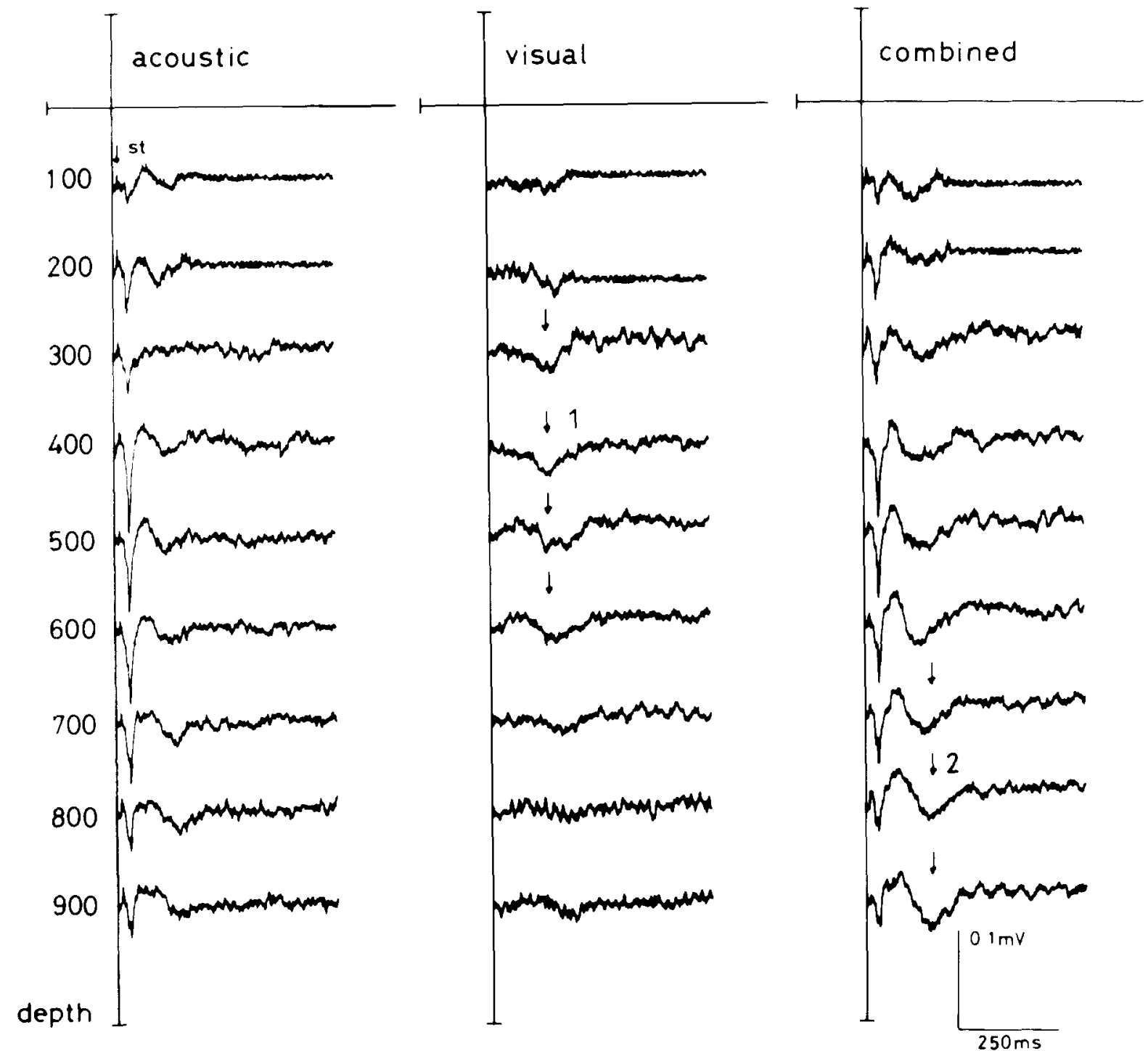

Fig. 1. Averaged evoked potentials recorded from the HVc region. Left, acoustic stimulation: middle. visual stimulation; right. combined vimulation. Average $64 \times$. bin width $500 \mu \mathrm{s}$. Arrows: 1. VEP: 2 . parts within the recordings. where visuat and acoustic stimuli may interate (see text). st, stimulus.

Nicolet signal averager. Storing and processing of the data was accomplished by a HP-85 microcomputer. This device also triggered the different stimuli and controlled the experimental procedure.

Besides very slow potential shifts of large amplitude. which can be seen in recordings throughout the brain and which were eliminated by a high pass filter with a cut-off frequency of $5 \mathrm{~Hz}$, faster fluctuations of large amplitude were detected within the HVc area. when the bird was not stimulated either visually or acoustically. Most of these large shifts disappeared with the application of stimuli. However. proper registration of averaged evoked potentials was very difficult due to the fact that one of these large asynchronous potentials could distort an average curve essentially. Thus, it was carefully detected throughout the experiments whether potentials developed stepwise in the course of the average procedure or whether they appeared as the result of one sweep.

With acoustic stimulation, a sharp negative-positive wave occurred with a peak latency of $25 \mathrm{~ms}$ for the negative potential and a duration of about $15 \mathrm{~ms}$. The shape and latency of this potential did not change 
essentially during its occurrence between 100 and $1000 \mu \mathrm{m}$ of depth as measured from the surface of the brain (Fig. 1).

These latencies are consistent with those of single cell recordings for acoustic neurons within the $\mathrm{HVc}$ area ${ }^{5.6 .10}$

The amplitude of the first negative potential increased between 100 and $200 \mu \mathrm{m}$ and decreased from 700 to $900 \mu \mathrm{m}$ of depth; however it could be detected down to a depth of about $2000 \mu \mathrm{m}$. Kelly and Nottebohm ${ }^{7}$ stated that $\mathrm{HVc}$ has an underlying shelf of acoustic neurons. This was confirmed by the studies of Katz and Gurneyt and Margoliash ${ }^{11}$, and is consistent with our finding that the acoustic influence is strongest at the ventral border of $\mathrm{HVc}$ (Fig. 2A).

With visual stimulation, a negative potential occurred from about 200 to $700 \mu \mathrm{m}$ from the surface.
Peak latency was about $140 \mathrm{~ms}$, the duration of the wave about $100 \mathrm{~ms}$ (Figs. 1, 2). Thus, in contrast to the acoustically evoked potential which could be recorded even outside the nucleus, the VEP was restricted to the area of $\mathrm{HVC}$. The amplitude of the VEP is lower than that of the acoustic potential, the shape seems to be more variable.

If both stimuli were combined, the potentials described above appeared simultaneously in the upper part of the recordings. The resulting waveform was apparently a summation of the two single evoked potentials. If one superimposes the two separate recordings of visually and acoustically evoked potentials by the computer, the same waveform as with double stimulation results (Fig. 3),

However, this statement holds true only for a depth from about 200 to $700 \mu \mathrm{m}$, the area where pure

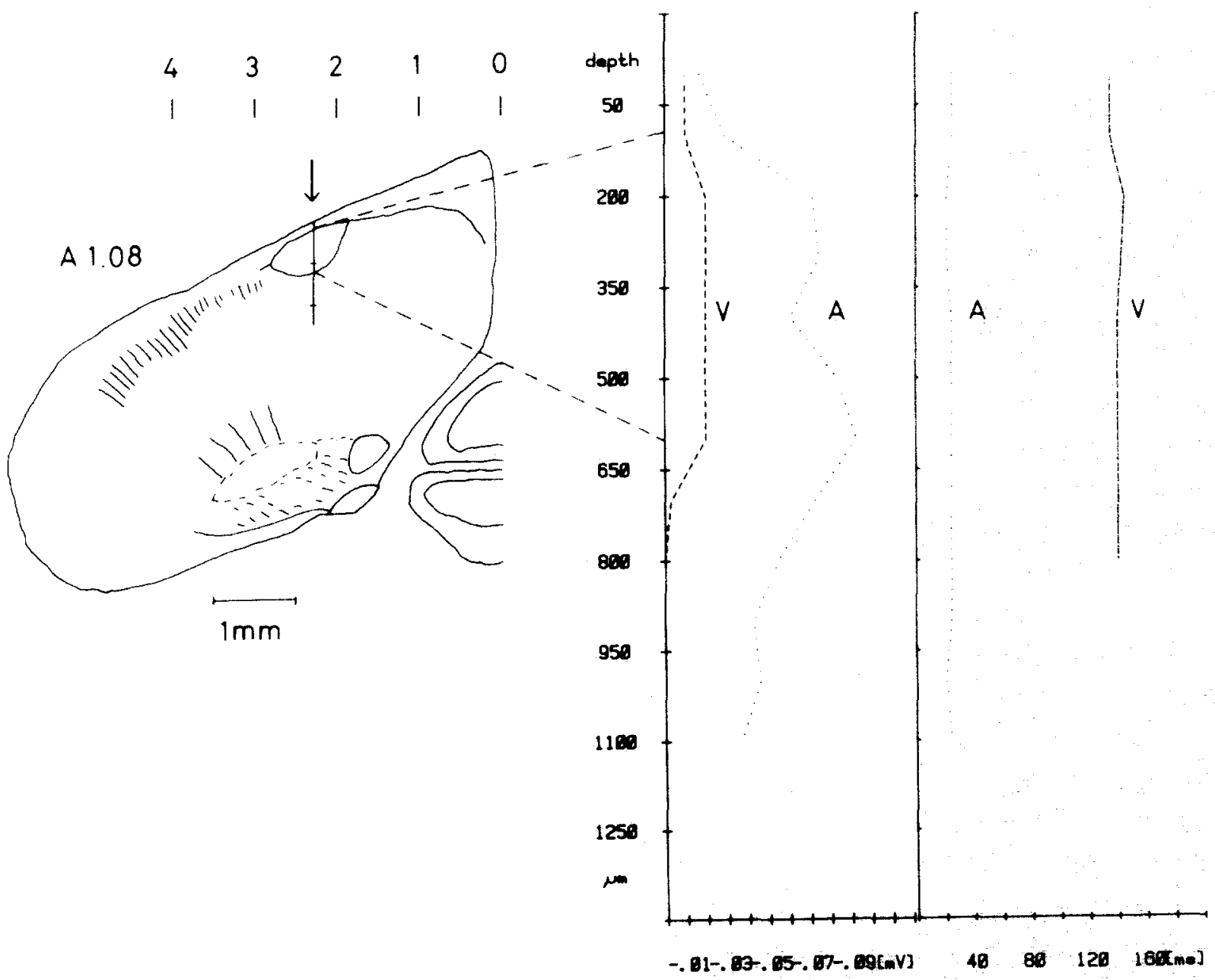

Fig. 2. Amplitude and latency diagram of acoustic (A) and visual (V) stimuli. Left: Electrode track with depth markings at 500 and $1000 \mathrm{um}$. 


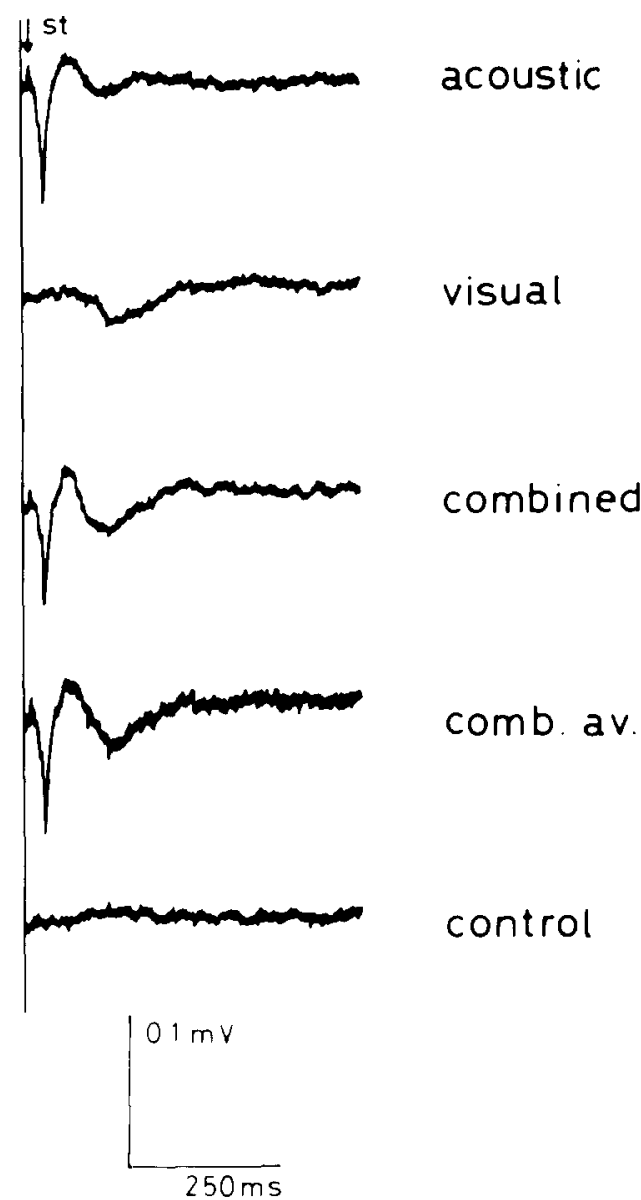

Fig. 3. Means of 5 recordings from a depth between 200 and 700 um to demonstrate the main features of the responses to different stimuli within HVc. Comb. av. recordings of pure acoustic or visual stimulations are added by the computer. Note the similarity to the curve of combined stimulation.

optic influence can be detected. At the ventral border of $\mathrm{HVC}$ and within the shelf region below the nucleus, the combination of stimuli resulted in an enhanced second negative wave if compared with pure acoustic stimulation (Figs. 1,2), although with solely visual stimulation no evoked potential is to be detected.

According to the anatomical findings, one can conclude from our results that the acoustic input to $\mathrm{HVC}$ derives from field $L$ of the neostriatum. In other experiments (Engelage and Bischof, in preparation) we recorded field $L$ peak latencies from 10 to about $30 \mathrm{~ms}$; the earliest waves may well be the trigger for the $H V_{c}$ potentials with a latency of $20-25 \mathrm{~ms}$. Again this is in good agreement with previous studies of other authorst 4.114 .

The large latency of the VEP (135-145 ms) makes it impossible to decicie which of the two visual path- ways provides the input to $\mathrm{HVc}$. The shortest latencies of VEPs in the ectostriatum, the telencephalic part of the tectofugal pathway, were recorded at about $40 \mathrm{~ms}$. Within the Wulst, the telencephalic region of the thalamofugal tract, shortest latencies were even at about 30-35 ms (unpublished results). As there is no direct connection demonstrated between HVc and visual pathways, we propose that additional regions of the telencephalon may be involved in the processing of visual information before it reaches HVc. Two features of our results make such a proposition likely. First, the comparably large latency cannot be solely a result of long fiber tracts. For example, the distance of the visual Wulst from the optic nerve is not much shorter than that of $H V \mathrm{c}$. Secondly, the shape of the VEP in HVc is not very sharp, perhaps as the result of a some processing steps which may desynchronize the neuronal activity elicited by light flashes.

Apparently, within the more dorsal parts of $\mathrm{HVC}$. there is no interaction between visual and acoustic inputs. If they are combined, the resulting waveform is primarily an addition of the two singly evoked waveforms. At the ventral border of the nucleus and the underlying shelf region, however, an interaction is very likely. Here it seems as if visual input facilitates acoustic input: the visual input, although no more detectable itself. enhances the reaction to the acoustic input. One has to consider that these results were obtained under anesthesia. This may severely influence the pattern of interaction between the two stimuli. However, it is more likely that an enhancement and not a diminution of interaction would be found in awake animals and with more natural stimulation.

Other, more complicated interactions may occur in addition in non-anesthetized preparations. Likewise, other stimulus programs as different spacing of the stimuli may reveal more information about the nature of interaction at this neuronal level. However. our results clearly demonstrate that there is visual input to $\mathrm{HVc}$; whether this input really has the function we can observe in our behavioral studies, that is to facilitate the action of the nucleus and the output of song, remains open to further research.

Our thanks are due to Mrs. Edda Cicissler for her assistance in preparing the figures. This research was supported by the Deutsche Forschungsgemeinschaft (Bi 245/3). 
1 Bischof, H. J., Unterscheidung zweidimensionaler Attrappen durch Zebrafinken, J. Orn., 118 (1977) 438-439.

2 Bischof, H. J., Reaktionen von Zebrafinkenmännchen auf zweidimensionale Attrappen: Einfluss von Prägung und Reizqualität, J. Orn., 121 (1980) 288-290.

3 Bischof, H. J., Böhner, J. and Sossinka, R., Influence of external stimulation on the quality of the song of the zebra finch (Taeniopygia guttata castanotis Gould), Z. Tierpsy. chol., 57 (1981) 261-267.

4 Immelmann, K., Experimentelle Untersuchungen über die biologische Bedeutung artspezifischer Merkmale beim $\mathrm{Ze}$ brafinken (Taeniopygia guttata castanotis Gould), Zool. $\mathrm{Jb.,} 86(1959)$ 438-593.

$5 \mathrm{Katz}, \mathrm{L}$. L., The avian motor system for song has multiple sites and types of auditory input, Soc. Neurosci. Abstr., \& (1983) 288.

$6 \mathrm{Katz}, \mathrm{L}$. L. and Gurney, M. E., Auditory responses in the zebra finch's motor system for song, Brain Research, 211 (1981) 192-197.

7 Kelly, D. P. and Nottebohm, F., Projections of a telencephalic auditory nucleus - field $\mathrm{L}$ - in the canary, J. comp. Neurol., 183 (1979) 455-470.

8 Konishi, M.. The role of auditory feedback in the control of vocalization in the white-crowned sparrow, $Z$. Tierpsychol., 22 (1965) 770-783.

9 Leppelsack, H. J., Analysis of song in the auditory pathway of songbirds. In J. P. Ewert et al. (Eds:), Advances in Vertebrate Neuroethology, Plenum, New York, 1983, 783-801.

10 Margoliash, D., Acoustic parameters underlying the responses of song-specific neurons in the white-crowned sparrow. J. Neurosci., 3 (1983) 1039-1057.

11 McCasland, J. S. and Konishi, M., Interaction between auditory and motor activities in an avian song control nucleus. Proc. nat. Acad. Sci. U.S.A., 78 (1981) 7815-7819.

12 Morris, D. The reproductive behaviour of the zebrafinch (Poephila guttata), Behaviour. 6(1954) 271-322.

13 Nottebohm. F., Brain pathways for vocal learning in birds: a review of the first 10 years, Progr. Psychobiol Physiol. Psychol., 9 (1980) 85-123.

14 Saini, K. D. and Leppelsack, H. J . Cell types of the auditory caudomedial neostriatum of the starling (Sturnus vulgaris), J. comp. Neurol., 198 (1981) 209-229.

15 Sossinka, R and Böhner, J., Song types in the zebra finch Poephila guttata castanotis, Z. Tierpsychol., 53 (1980) 123-132. 